Gut 1986, 27, S1, 61-66

\title{
Assessing nutritional state in inflammatory bowel disease
}

\author{
R V HEATLEY \\ Department of Medicine, St James's University Hospital, Leeds
}

SUMmARY Nutrient depletion is a common complication of inflammatory bowel disease, and some of the consequences can be severe. Although it is often easy to recognise the most severely undernourished subjects, those with lesser degrees of malnutrition may prove more difficult to detect. Measurements of many nutritional variables will be abnormal in patients with inflammatory bowel disease, especially in those with Crohn's disease, but are not always relevant to the clinical management of patients. Anthropometric means of assessment, in particular, measurement of mid arm circumference, can act as a simple, reproducible method of detecting those most at risk of appreciable undernutrition.

In what was probably one of the earliest descriptions of Crohn's disease emaciation was apparently a striking clinical consequence. ${ }^{1}$ Wasting and weight loss were also found to occur commonly in this disease in the original report by Crohn et al in 1932. ${ }^{2}$ Although overt weight loss is one of the most striking features of active inflammatory bowel disease, many more nutritional disturbances also occur. $^{3}$

Any patient with either ulcerative colitis or Crohn's disease can become severely wasted during an acute, unremitting attack of the disease. Chronic undernourishment, however, probably more commonly occurs in Crohn's disease than in ulcerative colitis. ${ }^{4}$ Apparently well nourished subjects may become deficient in one or more nutrients but remain otherwise well. Undernourished subjects, on the other hand, are usually at risk of multiple deficiencies. $^{5}$

The nutritional state of patients with inflammatory bowel disease is difficult to measure accurately and has, until recently, been only poorly documented. Traditionally, somewhat crude measures have been used, including overall clinical impression; changes in body weight; haemoglobin concentrations; and serum concentrations of folate, vitamin $B_{12}$, albumin, iron and total iron binding capacity. ${ }^{6}$ Many complications of severe inflammatory bowel disease, especially poor wound and fistula healing, muscle wasting, depressed humoral

Correspondence to: Dr R V Heatley, Department of Medicine, St James's University Hospital, Leeds LS9 7TF. England. and cellular immunity, and increased susceptibility to infection commonly occur in undernourished patients with other conditions. It is reasonable to assume that nutritional depletion is a major cause of these features in patients with inflammatory bowel disease, particularly as many can remit with nutritional treatment. ${ }^{7}$ Some of these features of undernourishment are, in fact, useful variables by which to assess nutritional state in patients with inflammatory bowel disease.

\section{Anthropometry}

Several large studies have documented weight loss in $70-80 \%$ of patients with Crohn's disease, and in some cases this was substantial. ${ }^{8-10}$ These studies do not, however, take into account the weight of patients before illness, and weight loss in a thin person may be more important than a similar loss in an obese patient. Recently the emphasis has changed and concentrated on relating weight and anthropometric measurements of muscle and subcutaneous fat to ideal standards to determine how far patients vary from the norm. Harries et al studied an unselected group of consecutive outpatients with Crohn's disease who were attending a gastrointestinal clinic. ${ }^{5}$ Many patients were considerably underweight and had significant reductions in muscle bulk and subcutaneous fat compared with a similar number of patients with ulcerative colitis and healthy subjects. About $20 \%$ of the patients with Crohn's disease were below $90 \%$ of their ideal weight, and particularly severely affected were 
males with diffuse small intestinal disease, especially that which recurred postoperatively, was currently active, and being treated with steroids. Lanfranchi $e t$ al found that $40 \%$ of 44 outpatients with Crohn's disease were below ideal weight, and they also reported similar reductions in anthropometric measurements. ${ }^{11}$ Both of these studies were carried out in patients who were not acutely ill, and they emphasise that a considerable degree of undernutrition exists even in this type of patient. Patients with colonic disease were not particularly undernourished, in contrast to the patients studied by Dyer and Dawson, ${ }^{12}$ a largely inpatient group with active disease. In the study by Harries $e t$ al $^{5}$ patients with ulcerative colitis had similar variables to healthy controls. None of these patients, however, had severe disease, and this probably explained their good state of nutrition, as in previous studies weight loss in ulcerative colitis was reported in 18 to $62 \%$ of patients. ${ }^{13}$ Furthermore, over $90 \%$ of the group with ulcerative colitis did not smoke, a factor which can affect body weight. ${ }^{14}$

One simple and apparently readily applicable method of identifying those patients most at risk of undernutrition is the measurement of the mid arm circumference on the non-dominant upper limb. Mid arm circumference measurements correlate positively with body weight in patients with Crohn's disease. Furthermore, it has been shown that when these measurements are expressed as a percentage of ideal values, the $90 \%$ of ideal standard (giving an absolute measurement in adults of $26.4 \mathrm{~cm}$ in men and $25.7 \mathrm{~cm}$ in women) is a useful reference point in patients with Crohn's disease. In a large group of patients with Crohn's disease, of those with mid arm circumference measurements below these values, half were more than $10 \%$ below ideal body weight. These subjects were also at risk of many other consequences of nutritional depletion, having reduced serum albumin, prealbumin, ferritin, calcium and vitamin D concentrations, haemoglobin values, urine creatinine excretion, and peripheral blood lymphocyte numbers, including $\mathrm{T}$ cell counts. ${ }^{5}{ }^{15}$ Furthermore, the mid arm circumference measurements were highly reproducible, even in obese patients and, compared with other anthropometric criteria including skinfold thickness and mid arm muscle circumference, showed least intraobserver and interobserver variation. ${ }^{16}$

Linear growth is a useful means of assessment in childhood. Some impairment may occur in $15-30 \%$ of children with Crohn's disease. ${ }^{17}{ }^{18}$ O'Donoghue and Dawson found that stunted growth was the presenting feature in six of 33 children referred to hospital and was also the most common physical abnormality. ${ }^{19}$

\section{Anaemia}

Anaemia of varying severity can be found in $50-70 \%$ of patients who are receiving treatment predominantly in hospital. ${ }^{8(1-22}$

\section{IRON DEFICIENCY}

A low serum iron may be found in $50-70 \%$ of cases of Crohn's disease, usually in association with a low total iron binding capacity. 21213 Bone marrow aspiration shows absent iron stores in $25-40 \%$ of patients, unrelated to the serum iron concentration. ${ }^{24} 25$ The serum ferritin is believed to reflect reticuloendothelial storage iron and is closely correlated with the amount of stainable iron in the bone marrow. ${ }^{26}$ Concentrations of less than $15 \mu \mathrm{g} / \mathrm{l}$ always indicate iron deficiency. In chronic inflammatory states, including inflammatory bowel disease, however, concentrations of $50 \mu \mathrm{g} / \mathrm{l}$ may be associated with true iron deficiency. ${ }^{25} 29$

Iron deficiency is the most important cause of anaemia in ulcerative colitis, usually through blood loss, and it tends to occur in patients with acute exacerbations. ${ }^{28-30}$

Using all of these tests, $25-50 \%$ of patients with Crohn's disease have iron deficiency. ${ }^{24}$ In ulcerative colitis up to two thirds of patients can be affected. ${ }^{31}$

\section{VITAMIN B 12 DEFICIENCY}

Diminished vitamin $\mathrm{B}_{12}$ absorption occurs in between one half and two thirds of patients with Crohn's disease and may be due to several different factors. ${ }^{12} 2232-36$ Deficiency is present, however, in only about one third of untreated patients with active disease. ${ }^{20} 21232432 \quad 3537-39$

\section{FOLIC ACID DEFICIENCY}

Differing incidences of folate depletion reflect the clinical heterogeneity of Crohn's disease: two thirds of the patients studied by Hoffbrand $e t$ al $^{24}$ were ill, while the same proportion of the group investigated by Krause $e t a l^{20}$ had undergone surgical resection with no recurrence, and were presumably well. Elsborg and Larsen ${ }^{38}$ found that $67 \%$ of patients with low serum and red cell folate concentrations had megaloblastic changes on bone marrow examination, often in the presence of normal haemoglobin concentrations. Overall, folic acid depletion probably occurs in about one third of patients with inflammatory bowel disease and active disease who are not receiving folate supplements. $^{21-2332353839}$
Albumin
Hypoproteinaemia has been recorded in various 
studies of Crohn's disease with an incidence of between $20-76 \% .^{20} 224041$ The most important cause of hypoproteinaemia is gastrointestinal protein loss, ${ }^{42}$ but hypoproteinaemia and oedema have been described in the absence of bowel symptoms. ${ }^{43}$ Hill et $a l^{44}$ found that postoperative complications were more common in patients with protein malnutrition, possibly as a result of impaired immunity and poor wound healing. In chronic ulcerative colitis albumin concentrations are usually normal.

\section{Minerals and vitamins}

It has become increasingly recognised that patients with Crohn's disease may suffer from various vitamin and trace element deficiencies. ${ }^{3}$ Although clinical manifestations of these deficiencies are unusual, measurement of serum concentrations of micronutrients should be considered in any detailed nutritional assessment.

\section{ELECTROLYTES AND TRACE ELEMENTS}

Hyponatraemia and hypochloraemia may be found in patients with Crohn's disease with active or recurrent disease,${ }^{45}$ and Beeken ${ }^{22}$ found low sodium concentrations in $10 \%$ of cases.

Potassium deficiency is usually present with a low plasma concentration and sometimes occurs when the plasma potassium is normal. ${ }^{4647}$ Correction of potassium values before surgery has been shown to reduce the complication rate and mortality. ${ }^{47}$

Hypocalcaemia has been reported to occur commonly in Crohn's disease ${ }^{22} 40$ but values must be related to the albumin concentration. ${ }^{41}$ Hypocalcaemia usually occurs in association with hypoalbuminaemia, and if appropriate corrections are made, then true hypocalcaemia is relatively uncommon. Krawitt et al ${ }^{48}$ carried out a detailed study on 31 patients and found normal serum calcium concentrations, absorption, and endogenous faecal calcium excretion compared with those of controls.

Magnesium deficiency was not widely appreciated as a complication of Crohn's disease until 1970, when Gerlach et $a l^{49}$ described four patients with symptomatic hypomagnesaemia. Dependence on serum magnesium concentrations for diagnosis will lead to underdiagnosis of the condition. Beeken ${ }^{22}$ found hypomagnesaemia in only nine of 63 patients. Main et al, ${ }^{50}$ however, using serum and urine concentrations together as an indicator of magnesium state, found that 15 of 17 patients admitted to hospital with severe disease were deficient in magnesium. Swedish workers found clinically important magnesium deficiency in $30 \%$ of patients following intestinal resection. Diagnosis depended on muscle magnesium concentrations, which were often low in the presence of normal serum concentrations. ${ }^{51}$

Low plasma zinc concentrations have been reported in up to $40 \%$ of patients with Crohn's disease and often in association with impaired taste capacity. ${ }^{52-55}$ In contrast, others found normal plasma and urine zinc concentrations. ${ }^{56}{ }^{57}$ In many of the studies there was a correlation between concentrations of plasma zinc and albumin.

\section{VITAMINS}

Various deficiency states affecting both water soluble (vitamin B complex and vitamin C) and fat soluble (vitamins $A, D, E$, and $K$ ) vitamins have been reported in patients with Crohn's disease. ${ }^{3}$ The relevance to the clinical condition has not been well documented and as assays for these vitamins are not generally available measurements have little part to play in clinical practice. It is, however, important to bear these entities in mind in patients with complex nutritional disturbances.

\section{Fat and carbohydrate absorption}

Steatorrhoea can be found in up to $30 \%$ of patients with Crohn's disease. ${ }^{22} 3441$ Both the length of diseased small bowel and the extent of surgical resection are important determinants of the degree of steatorrhoea. In practice, however, the problem is often masked because of the associated anorexia and reduced fat intake. ${ }^{58}$ Steatorrhoea is important because it reflects malabsorption not only of fat but also of other substances. Most of the patients studied by Pimparker et $a l^{40}$ who had steatorrhoea also had hypoalbuminaemia, hypoprothrombinaemia, and vitamin $B_{12}$ malabsorption.

Xylose absorption has been found to be impaired in some studies ${ }^{22} 35$ but, on the whole, it is normal unless the entire jejunum and ileum are affected by the inflammatory process. ${ }^{34}{ }^{41}$ Lactose absorption is also generally regarded as being normal in inflammatory bowel disease. ${ }^{59}$

\section{Assessment of nutritional intake}

Dietary assessment of patients with chronic inflammatory bowel disease attending outpatient clinics has shown that most patients have what would normally be regarded as an adequate nutrient intake, although this may well not be sufficient for the needs of those with Crohn's disease. ${ }^{60}$ It has been suggested that prolonged inadequate caloric intake is probably a major cause of growth failure in children with Crohn's disease. ${ }^{61} 62$ 


\section{Measurement of immune functions}

Undernourished patients with Crohn's disease have considerable reductions in total lymphocyte numbers, total $\mathrm{T}$ lymphocyte and $\mathrm{T}$ subset counts, a reduced proportion of monocytes capable of ingesting latex particles, and reduced in vitro immunoglobulin production at low lymphocyte concentrations. ${ }^{63}$ As few of these tests are routinely available they are of little help in normal clinical practice but may help in nutritional assessment for research purposes.

\section{Conclusion}

Malnutrition is common in patients with active inflammatory bowel disease, especially Crohn's disease. Weight loss is widely used as a simple means of identifying patients at risk of nutritional depletion, but it may be an unreliable indicator if it depends on the patient's memory, routine hospital records, or if oedema occurs as a result of hypoalbuminaemia. It is usually not difficult to recognise patients who are severely undernourished, but it may be much more difficult in those with lesser degrees of nutritional depletion. A wide range of nutritional disturbances can be found, particularly in ill patients with Crohn's disease. As more sophisticated tests to assess nutritional state become available so are more and more deficiency states being recognised as complications of inflammatory bowel disease. It is probably important to recognise appreciable nutritional deficiencies at an early stage so that appropriate treatment can be started; otherwise many patients will suffer unnecessarily from the consequences of deprivation of vital nutrients that may cause considerable morbidity. Some patients will require nutritional supplements. Careful monitoring of blood films and serum concentrations of folate, vitamin $\mathrm{B}_{12}$, iron, and ferritin will act as a guide for replacement treatment. Serum calcium (and albumin), and alkaline phosphatase activity, although poor overall indicators, may be of some value in the detection of osteomalacia. These simple screening tests are likely to identify the most severe nutritional consequences of inflammatory bowel disease. Nutritional defects may, however, have more subtle effects; iron and zinc deficiency can be associated with impaired immune competence ${ }^{64}$ and hypomagnesaemia may be associated with parathyroid failure. ${ }^{65}$ Although the classical manifestations of nutritional depletion are uncommon, subclinical deficiencies, which may have clinical relevance, are by no means rare.

On clinical grounds, it is difficult to identify the "at risk" patient who attends the outpatient department. Simple anthropometric measurements, especially that of the mid arm circumference, provide a simple, reproducible, and convenient way of achieving this and help to identify those patients with both clinical and biochemical features of malnutrition. Consideration should be given to including these measurements in any formal assessment of nutritional state in patients with inflammatory bowel disease.

\section{References}

1 Combe C, Saunders W. A singular case of stricture and thickening of the ileum. Medical Transactions of the College of Physicians of London 1813; 4: 16-21.

2 Crohn BB, Ginzburg L, Oppenheimer GD. Regional ileitis. A pathologic and clinical entity. JAMA 1932; 99: 1323-29.

3 Harries AD, Heatley RV. Nutritional disturbances in Crohn's disease. Postgrad Med J 1983; 59: 690-7.

4 Harries AD, Jones L, Heatley RV, Rhodes J, Fitzsimons E. Mid-arm circumference as simple means of identifying malnutrition in Crohn's disease. Br Med J 1982; 285: 1317-8.

5 Harries AD, Jones LA, Heatley RV, Rhodes J. Inflammatory Bowel Disease: an anthropometric Study. Hum Nutr Clin Nutr 1982; 36C: 307-13.

6 Harries AD, Heatley RV. Nutrition in inflammatory bowel disease. In: Heatley RV, Kellehur J, Losowsky MS, eds. Clinical nutrition in gastroenterology. London: Churchill Livingstone, 1986.

7 Harries AD, Jones LA, Danis V, et al. Controlled trial of supplemented oral nutrition in Crohn's disease. Lancet 1983; i: 887-90.

8 Van Patter WN, Bargen JA, Dockerty MB, Feldman WH, Mayo CW, Waugh JM. Regional enteritis. Gastroenterology 1954; 26: 347-450.

9 Crohn BB, Yarnis H. Regional ileitis. 2nd ed. London: Grune and Stratton, 1958.

10 Mekhjian HS, Switz DM, Melnyk CS, Rankin GB, Brooks RK. Clinical features and natural history of Crohn's disease. Gastroenterology 1979; 77: 898-906.

11 Lanfranchi GA, Brignola $\mathrm{C}$, Campieri $\mathrm{M}$, et al. Assessment of nutritional status in Crohn's disase in remission or low activity. Hepatogastroenterology 1984; 31: $129-32$.

12 Dyer NH, Dawson AM. Malnutrition and malabsorption in Crohn's disease with reference to the effect of surgery. Br J Surg 1973; 60: 134-40.

13 Goligher JC, deDombal FT, McKwatts J, Watkinson JG. Ulcerative colitis. London: Balliere Tindall Cassell, 1968.

14 Harries AD, Jones L, Heatley RV, Rhodes J. Smoking habits and inflammatory bowel disease: effect on nutrition. Br Med J 1982; 284: 1161.

15 Harries AD, Fitzsimons E, Dew MJ, Heatley RV, Rhodes J. Association between iron deficiency anaemia and mid-arm circumference in Crohn's disease. Hum Nutr Clin Nutr 1984; 38C: 47-53.

16 Harries AD, Jones LA, Heatley RV, Newcombe RG, 
Rhodes J. Precision of anthropometric measurements: the value of mid-arm circumference. Clin Nutr 1984; 2: 193-6.

17 McCaffery TD, Nasr K, Lawrence AM, Kirsner JB. Severe growth retardation in children with inflammatory bowel disease. Pediatrics 1970; 45: 386-93.

18 Burbige EJ, Huang S, Bayless TM. Clinical manifestations of Crohn's disease in children and adolescents. Pediatrics 1975; 55: 866-71.

19 O'Donoghue DP, Dawson AM. Crohn's disease in childhood. Arch Dis Child 1977; 52: 627-32.

20 Krause U, Bergman L, Norlen BJ. Crohn's disease. A clinical study based on 186 patients. Scand J Gastroenterol 1971; 6: 97-108.

21 Dyer NH, Child JA, Mollin DL, Dawson AM. Anaemia in Crohn's disease. $Q J$ Med 1972; 41: 419-36.

22 Beeken WL. Remediable defects in Crohn's disease. A prospective study of 63 patients. Arch Intern Med 1975 135: $686-90$.

23 Eade MN, Cooke WT, Williams JA. Clinical and haematologic features of Crohn's disease. Surg Gynecol Obstet 1972; 134: 43-46.

24 Hoffbrand AV, Stewart JS, Booth CC, Mollin DL. Folate deficiency in Crohn's disease: incidence, pathogenesis and treatment. Lancet 1968; ii: 71-5.

25 Thomson ABR, Brust R, Ali MAM, Mant MJ, Valberg LS. Iron deficiency in inflammatory bowel disease. Diagnostic efficacy of serum ferritin. Am J Dig Dis 1978; 23: 705-9.

26 Jacobs A, Worwood M. Ferritin in serum. Clinical and biochemical implications. New Engl J Med 1975; 292: 951-6.

27 Worwood M. Serum ferritin. In: Cook JD, ed. Methods in haematology. Iron. Edinburgh: Churchill Livingstone 1980: 59-89.

28 Beal RW, Skyring AP, McRae J, Firkin BG. The anemia of ulcerative colitis. Gastroenterology 1963; 45: 589-603.

29 Edwards FC, Truelove SC. The course and prognosis of ulcerative colitis. Part III. Complications. Gut 1964; 5: $1-15$.

30 Ormerod TP. Anaemia in ulcerative colitis. Proceedings of the Royal Society of Medicine 1968; 61: 931.

31 Driscoll RH, Rosenberg IH. Total parenteral nutrition in inflammatory bowel disease. Med Clin North Am 1978; 62: 185-201.

32 Dotevall G, Kock NG. Absorption studies in regional enterocolitis. Scand J Gastroenterol 1968; 3: 293-8.

33 Hertzberg JN, Myren S, Semb LS. Regional enterocolitis (Crohn's disease). Absorption studies after surgical treatment. Scand J Gastroenterol 1969; 4: 569-73.

34 Smith AN, Balfour TW. Malabsorption in Crohn's disease. Clin Gastroenterol 1972: 433-48.

35 Gerson CD, Cohen N, Janowitz HD. Small intestinal absorptive function in regional enteritis. Gastroenterology 1973; 64: 907-12.

36 Fausa $\mathrm{O}$. Vitamin $\mathrm{B}_{12}$ absorption in intestinal diseases (coeliac disease, dermatitis herpetiformis, ulcerative colitis, Crohn's disease, jejuno-ileal shunting). Scand J Gastroenterol 1974; (suppl 29) 9: 75-9.

37 Meynell MJ, Cooke WT, Cox EV, Gaddie R. Serum- cyanacobalamin level in chronic intestinal disorders. Lancet 1957; i: 901-4.

38 Elsborg L, Larsen L. Folate deficiency in chronic inflammatory bowel disease. Scand $J$ Gastroenterol 1979; 14: 1019-24.

39 Kyle J. Crohn's disease. London: Heinemann, 1972.

40 Pimparker BC, Mouhran Y, Bockus HL. Nutritional and metabolic studies in non-specific regional enteritis and enterocolitis; correlation with anatomic site of involvement. Proceedings of the International Congress of Gastroenterology 1960: 227-47.

41 Dyer NH. Studies on Crohn's disease. Cambridge: University of Cambridge. 1970. (Thesis.)

42 Beeken WL, Busch HJ, Sylwester DL. Intestinal protein loss in Crohn's disease. Gastroenterology 1972; 62: $207-15$.

43 Cobb TC, Robson MC. Regional enteritis presenting as hypoproteinaemia without intestinal symptoms. JAMA 1969; 207: 1351-2.

44 Hill GL, Blackett RL, Pickford IR, Bradley JA. A survey of protein nutrition in patients with inflammatory bowel disease - a rational basis for nutritional therapy. Br J Surg 1977; 64: 894-6.

45 Kiefer ED. Recurrent regional ileitis. Surg Clin North Am 1955; 35: 801-7.

46 Cooke WT. Nutritional and metabolic factors in the aetiology and treatment of regional ileitis. Ann $R$ Coll Surg Engl 1955; 17: 137-58.

47 Lehr L, Schober O, Hundeshagen H, Pilchlmayr R. Body potassium depletion in Crohn's disease requiring specific nutritional preparation for surgery. Scand $J$ Gastroenterol 1982; 17 (suppl 78): A1974.

48 Krawitt EL, Beeken WL, Janney CD. Calcium absorption in Crohn's disease. Gastroenterology 1976; 71: 251-4.

49 Gerlach K, Morowitz DA, Kirsner JB. Symptomatic hypomagnesemia complicating regional enteritis. Gastroenterology 1970; 59: 567-74.

50 Main $\mathrm{ANH}$, Morgan RJ, Russell RI, et al. $\mathrm{Mg}$ deficiency in chronic inflammatory bowel disease and requirements during intravenous nutrition. JPEN 1981; 5: $15-19$.

51 Hessov I, Hasselblad C, Fasth S, Hulten L. Magnesium deficiency after small bowel resection for Crohn's disease. Scand J Gastroenterol 1982; 17 (suppl 78): A1973.

52 Solomons NW, Rosenberg IH, Sandstead HH, VoKhactu KP. Zinc deficiency in Crohn's disease. Digestion 1977; 16: 87-95.

53 McClain C, Soutor C, Zieve L. Zinc deficiency: a complication of Crohn's disease. Gastroenterology 1980; 78: 272-9.

54 Sturniolo GC, Molokhia MM, Shields R, Turnberg LA. Zinc absorption in Crohn's disease. Gut 1980; 21 : 387-91.

55 Penny WJ, Mayberry JF, Aggett PJ, Gilbert JO, Newcombe RG, Rhodes J. Relationship between trace elements, sugar consumption and taste in Crohn's disease. Gut 1983; 24: 288-92.

56 Mills PR, Fell GS. Zinc and inflammatory bowel disease. Am J Clin Nutr 1979; 32: 2172-3. 
57 Fleming CR, Huizenga KA, McCall JR, Gildea J, Dennis R. Zinc nutrition in Crohn's disease. Dig Dis Sci 1981; 26: 865-70.

58 Burke J. The treatment of steatorrhoea in Crohn's disease. $\mathrm{Br}$ Med J 1953; 1: 239-42.

59 Gudmand-Hoyer E, Jarnum S. Incidence and clinical significance of lactose malabsorption in ulcerative colitis and Crohn's disease. Gut 1970; 11: 338-43.

60 Jones LA, Harries AD, Rhodes J, Heatley RV. Normal energy intake in undernourished patients with Crohn's disease. $\mathrm{Br}$ Med J 1984; 288: 193.

61 Kirschner BS, Klich JR, Kalman SS, De Favaro MV, Rosenberg IH. Reversal of growth retardation in
Crohn's disease with therapy emphasizing oral nutritional restitution. Gastroenterology 1981; 80: 10-15.

62 Kirschner BS, Voinchet O, Rosenberg IH. Growth retardation in inflammatory bowel disease. Gastroenterology 1978; 75: 504-11.

63 Harries AD, Danis VA, Heatley RV. Influence of nutritional status on immune functions in patients with Crohn's disease. Gut 1984; 25: 465-72.

64 Dowd PS, Heatley RV. The influence of undernutrition on immunity. Clin Sci 1984; 66: 241-8.

65 Rude RK, Oldham SB, Singer FR. Functional hypoparathyroidism and parathyroid hormone endorgan resistance in human magnesium deficiency. Clin Endocrinol 1976; 5: 209-24. 